\title{
Desain Efisiensi Energi Penggunaan Lampu di lantai 5 Perpustakaan ITS
}

\author{
Suyatno*, Maslahah, dan Susilo Indrawati \\ Departemen Fisika, Fakultas Sains dan Analitika Data, Institut Teknologi Sepuluh Nopember (ITS), \\ Kampus ITS Sukolilo, Surabaya 60111
}

\begin{abstract}
Intisari
Penelitian ini dilakukan untuk mengetahui besar dan kemerataan nilai kuat pencahayaan di ruang baca perpustakaan lantai 5 ITS Surabaya dengan melakukan pengukuran dan simulasi menggunakan software DIALux4.13 untuk kondisi existing dan perbaikan. Nilai kuat pencahayaan minimal standar untuk ruang perpustakaan adalah 300 lux. Pengukuran kuat pencahayaan dilakukan menggunakan luxmeter pada 31 titik dengan ketinggian 1 meter di atas bidang kerja. Pada kondisi eksisting, jumlah lampu yang dipakai adalah 112 lampu Philips tipe 1xTL-D36W/54-765 dengan daya 43 Watt dan menghasilkan fluks luminus 2500 lumen, 19 lampu 2xTLD36W/54-765 dengan flux luminus 5000 lumen berdaya 85 Watt, dan 6 buah lampu philips RS061B 1xLED tipe 5-36-/830 berdaya 6 Watt dengan fluks luminus 480 lumen. Berdasarkan hasil pengukuran kondisi existing diperoleh nilai kuat pencahayaan rata-rata 90,27 lux, yang menunjukkan belum memenuhi standart untuk ruang baca. Sedangkan untuk keseragamannya sebesar 0,48 yang masih di bawah standart 0,6 . Sementara penggunaan listrik memerlukan daya total sebesar 6467 Watt. Pada simulasi perbaikan, digunakan lampu TL philips LL 121X 1xLED45S/840 O 4200 lumen sebanyak 129 lampu berdaya 32 Watt. Hasil simulasi didapatkan hasil kuat pencahayaan rata-rata 344 lux dan kemerataannya 0,62. Penggunaan jenis lampu LED ini juga mampu menurunkan penggunaan daya hingga $36 \%$ lebih efisien dibandingkan dengan kondisi awal.
\end{abstract}

\begin{abstract}
This research was conducted to determine the magnitude and evenness of the value of the strong lighting on the 5th floor of the reading room at the ITS Surabaya library by measuring and simulating using DIALux4.13 software for existing and repair conditions. The minimum standard of strong lighting value for a library room is 300 lux. Measurement of lighting strength is done using a lux meter at 31 points with a height of 1 meter above the work area. In existing conditions, the number of lamps used is 112 Philips lamps 1xTL-D36W / 54-765 with 43 Watts of power and produces 2500 lumens flux lumens, 19 2xTL-D36W / 54-765 lamps with 5000 lumens flux with 85 Watt lumens, and 6 Philips RS061B 1xLED lamps type 5-36- / 8306 Watt powered with 480 lumens luminous flux. Based on the results of the measurement of the existing conditions obtained an average value of 90.27 lux lighting, which shows that it has not met the standard for the reading room. As for the uniformity of 0.48 which is still below the standard 0.6. While the use of electricity requires a total power of 6467 Watt. In the repair simulation, TL Philips Philips 121X 1xLED45S / 840 O 4200-lumen lights are used as many as 12932 watt lamps. The simulation results obtained an average lighting strength of 344 lux and an evenness of 0.62 . The use of this type of LED light is also able to reduce power usage by $36 \%$ more efficiently compared to the initial conditions.
\end{abstract}

Keywords: desain pencahayaan; DIALux 4.13; kuat pencahayaan; perpustakaan; uniformity.

*Corresponding author: kangyatno@physics.its.ac.id

http://dx.doi.org/10.12962/j24604682.v16i3.6223

2460-4682 (C)Departemen Fisika, FSAD-ITS

\section{PENDAHULUAN}

Salah satu faktor yang perlu diperhatikan dalam perancangan ruangan adalah pencahayaan. Penggunaan sumber cahaya bertujuan untuk mempermudah pelaksanaan kegiatan di dalam maupun di luar ruangan dan memunculkan efek visual yang diinginkan merupakan pengertian dari proses pencahayaan[1]. Pencahayaan secara umum terdiri atas pencahayaan alami yang berasal dari matahari dan pencahayaan buatan yang berasal dari lampu, lilin, dan lain-lain. Pengelo- laan pencahayaan yang tepat, menguntungkan, dan berkelanjutan pada gedung perpustakaan merupakan hal yang penting. Hal tersebut berkaitan dengan besarnya jumlah energi yang dikonsumsi, kebutuhan penerangan pembaca buku, dan untuk keperluan lain seperti fasilitas digital berupa komputer.

Terdapat beberapa faktor yang dapat digunakan untuk mengetahui karakteristik dari kualitas pencahayaan di indoor workplace yaitu tingkat iluminansi, uniformity, UGR (Unified Glare Rating), dan CRI (Colour Rendering Indeks) [2]. Tingkat iluminasi (pencahayaan) suatu ruangan pada umum- 


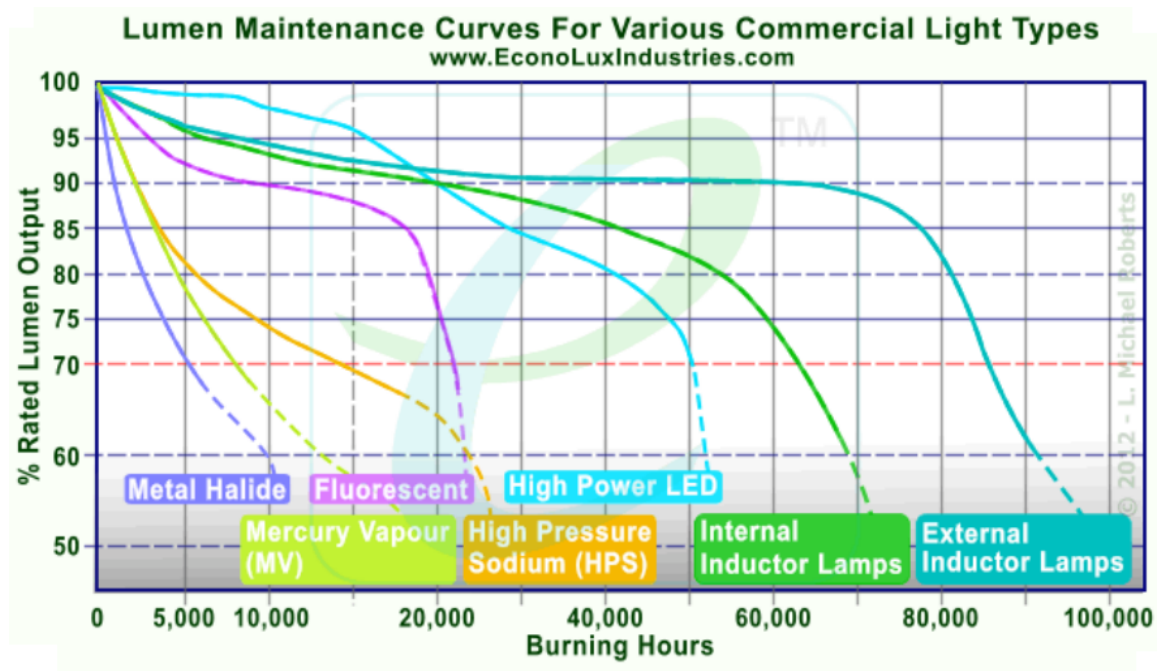

Gambar 1: Grafik LLD (Lamp Lumen Depreciation).

nya didefinisikan sebagai tingkat pencahayaan rata-rata pada bidang kerja. Berdasarkan SNI 03-6575-2001 penghitungan tingkat iluminansi (E) dapat dilakukan dengan menggunakan persamaan: [3]

$$
E_{\text {rerata }}=\frac{F_{\text {total }} \times k_{p} \times k_{d}}{A}
$$

$\mathrm{F}_{\text {total }}=$ fluks luminus total dari semua lampu yang menerangi bidang kerja (lumen), A = luas bidang kerja $\left(\mathrm{m}^{2}\right), \mathrm{k}_{p}=$ koefisien penggunaan, $\mathrm{k}_{d}=$ koefisien depresiasi (penyusutan).

Pengertian dari uniformity yaitu perbandingan iluminasi minimum $\left(\mathrm{E}_{\text {min }}\right)$ terhadap iluminansi rata-rata $\left(\mathrm{E}_{\text {rerata }}\right)$. Secara matematis dirumuskan sebagai

$$
U_{\circ}=\frac{E_{\text {min }}}{E_{\text {rerata }}}
$$

UGR merupakan efek yang ditimbulkan oleh daerah yang terkena penyinaran sehingga pada bidang pandang menjadi terang dan mungkin dapat menyilaukan serta menimbulkan ketidaknyamanan pandangan. Colour rendering menunjukkan kemampuan dari sumber cahaya dalam membentuk warna permukaan yang disinari tampak alami jika dibandingkan dengan sumber cahaya referensi. Perbandingan tersebut dinamakan CRI. Rentang nilai CRI adalah 0-100, dengan nilai CRI 100 berarti bahwa cahaya menyebabkan tidak ada perubahan warna pada objek yang terkena cahaya [2, 4].

Pengaturan pencahayaan yang sesuai dengan fungsi ruangan dapat mengefisiensikan daya yang dipakai sehingga dapat menghemat energi listrik. Dalam masa pemakaian lampu pada ruangan terdapat faktor yang mempengaruhi berkurangnya kemampuan sumber cahaya dalam memancarkan cahaya yang disebut sebagai LLF (Light Loss Factor). LLF dapat diperoleh dengan menggunakan persamaan:

$$
L L F=L L D \times L D D \times B F
$$

dengan LLD (Lamp Lumen Depreciation), LDD (Luminaire Dirt Depreciation), BF (Balast Factor).

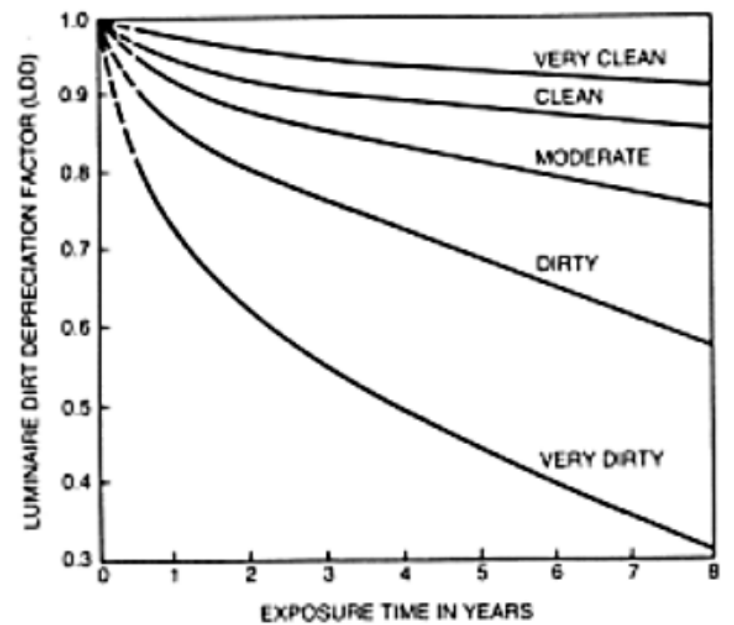

Gambar 2: Grafik LDD (Luminaire Dirt Depreciation).

Pengertian dari LLD yaitu penurunan nilai lumen yang dikeluarkan oleh lampu seiring waktu yang menyebabkan turunnya tingkat kemampuan memancarkan cahaya dari lampu tersebut. Grafik LLD dari beberapa lampu ditampilkan pada Gambar 1. Sedangkan Gambar 2 merupakan grafik yang menggambarkan hubungan antara kekotoran lampu yang digunakan terhadap performa penggunaan lampu tersebut. Pengaruh adanya debu pada bagian dalam refraktor, reflektor, dan lampu adalah pada berkurangnya nilai lumen yang dipancarkan $[5,6]$.

Dalam makalah ini dibahas tentang evaluasi kuat pencahayaan serta optimalisasi perbaikaan sistem pencahayaan melalui simulasi. Adapun standart yang digunakan adalah SNI-16-7062-2004 [7] tentang pengukuran intensitas penerangan di tempat kerja di perpustakaan. Pengukuran dilakukan menggunakan lux meter. Untuk perpustakaan, penerangan yang diukur adalah penerangan umum dan penerangan setempat pada meja baca dan rak-rak buku. Jarak titik 


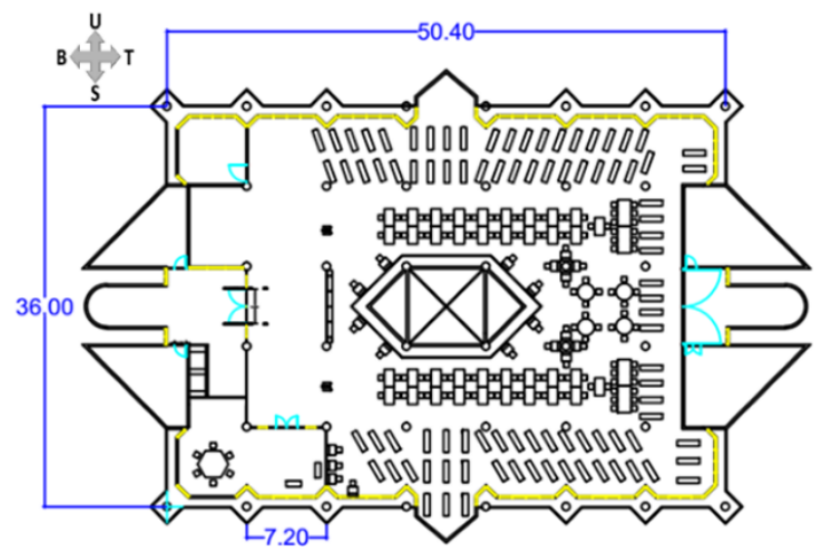

Gambar 3: Desain tampak atas Perpustakaan ITS lantai 5.

pengambilan data kuat pencahayaan ditentukan berdasarkan luas ruangan yang diukur. Berdasarkan hasil pengukuran tersebut kemudian dilakukan simulasi untuk perbaikan kualitas pencahayaan serta efisisensi energi listrik yang yang digunakan. Sementara nilai acuan yang dituju adalah mengacu pada standar EN 12464-1 yaitu sebesar 500 lux area membaca yaitu sebesar 200 lux, untuk daerah rak buku [8].

\section{METODOLOGI}

Untuk mendapatkan pencahayaan yang optimal di ruang baca perpustakaan, optimasi kuat pencahaan dilakukan berdasarkan pada kondisi eksisting melalui simulasi. Tujuannya adalah agar kuat pencahayaan di ruang tersebut sesuai dengan yang disyaratkan sebagai ruang perpustakaan. Adapun tahapan-tahapan yang dilakukan dalam optimasi pecahayaan di ruang perpustakaan adalah sebagai berikut:

\section{Tahap observasi awal}

Pada tahap ini, dilakukan peninjauan (observasi) kondisi di Perpustakaan ITS Surabaya lantai 5 meliputi pengukuran dimensi ruangan, pengamatan warna ruangan, dan material yang digunakan pada permukaan ruangan. Observasi juga dilakukan pada kondisi pencahayaan berupa lampu di ruangan. Gambar 3 menunjukkan denah ruang baca perpustakaan ITS.

Berdasarkan Gambar 3, ukuran dan dimensi dari ruang baca Perpustakaan ITS Surabaya lantai 5 terdiri atas luas gedung lantai 5 yaitu $50,4 \times 36\left(=1814,4 \mathrm{~m}^{2}\right)$, luas ruang baca $1381,58 \mathrm{~m}^{2}$, ketinggian ruangan $2,8 \mathrm{~m}$, serta ketinggian lampu dari lantai adalah $2,8 \mathrm{~m}$.

\section{Proses pengukuran kuat pencahayaan}

Proses pengambilan data pada tahap ini mengacu pada SNI 16-7062-2004 [6] mengenai pengukuran intensitas penerangan di tempat kerja. Di dalamnya terdapat kriteria tertentu untuk luas ruangan yang diukur. Untuk ruangan perpustakaan lantai 5 yang memiliki luasan lebih dari $100 \mathrm{~m}^{2}$ titik-titik pengukuran dibuat dengan jarak antar titik adalah $6 \times 6$ meter. Posisi ketinggian pengukuran adalah 1 meter di atas bidang
TABEL I: Hasil pengukuran nilai kuat pencahayaan umum.

\begin{tabular}{lcccc}
\hline \hline $\begin{array}{l}\text { Objek } \\
\begin{array}{l}\text { Pengu- } \\
\text { kuran }\end{array}\end{array}$ & $\begin{array}{l}\mathrm{E}_{\text {min }} \\
(\text { Lux }\end{array}$ & $\begin{array}{c}\mathrm{E}_{\text {maks }} \\
\text { (Lux) }\end{array}$ & $\begin{array}{c}\mathrm{E}_{\text {rerata }} \\
(\text { Lux })\end{array}$ & $\begin{array}{c}\text { Kesera- } \\
\text { gaman } \\
\mathrm{U}_{\circ}\end{array}$ \\
\hline & & & & \\
Lampu menyala & 43,3 & 130,8 & 90,27 & 0,48 \\
Lampu mati & 1,12 & 71,3 & 13,13 & 0,09 \\
\hline \hline
\end{tabular}

kerja. Sedangkan untuk pengukuran kuat pencahayaan setempat titik-titik pengukurannya dilakukan pada tiap rak dan meja baca. Pengukuran kuat pencahayaan dilakukan dengan menggunakan lux meter tipe Lutron LX-1108.

\section{Proses pengolahan data}

Data kuat pencahayaan yang telah didapat dari proses pengukuran kemudian dihitung nilai rata-ratanya serta dicatat nilai maksimum dan minimumnya. Selain itu juga dibuat maping dengan menggunakan software Surfer 11 untuk mengetahui keseragaman distribusi cahaya dari lampu yang digunakan.

\section{Proses simulasi menggunakan software DIALux 4.13}

Hasil pengukuran dimensi ruangan, pengamatan warna permukaan ruangan, jenis lampu, posisi lampu, dan jumlah lampu yang digunakan disimulasikan dengan menggunakan software DIALux 4.13. Hasil simulasi tersebut kemudian dibandingkan dengan data yang didapatkan dari pengukuran dengan kondisi exisitng yang telah dilakukan agar nilai kuat pencahaan sesuai dengan standar ruang perpustakaan.

\section{HASIL DAN PEMBAHASAN}

\section{Hasil pengukuran kuat pencahayaan umum}

Pengukuran kuat pencahayaan secara umum dilakukan pada seluruh area di Perpustakaan ITS Surabaya lantai 5 yang mengacu pada SNI [6]. Jumlah titik pengukuran adalah 31 titik, dan pengukuran dilakukan pada pukul 08.00-11.00 WIB. Pada kondisi ruangan sebenarnya, terdapat sejumlah 131 armatur, dengan rincian 63 armatur lampu phillips tipe 1xTLD36W/54-765 dengan fluks luminusnya sebesar 2500 lumen dan 68 armatur lampu phillips tipe 2xTL-D36W/54-765 dengan flux luminus sebesar 5000 lumen. Selain itu, terdapat 6 buah lampu philips RS061B 1xLED tipe 5-36-/830 berdaya 6 Watt dengan fluks luminus 480 lumen. Tabel I menunjukkan data hasil pengukuran.

Berdasarkan Tabel I, nilai kuat pencahayaan ketika kondisi seluruh lampu dimatikan nilainya rendah. $\mathrm{E}_{\min }$ adalah nilai kuat pencahayaan minimun yang terukur oleh luxmeter dan $\mathrm{E}_{\text {maks }}$ adalah nilai kuat pencahayaan maksimum. Berdasarkan Tabel I tersebut terlihat bahwa pencahayaan alami di ruang tersebut sangat kecil, meskipun terdapat jendela dibeberapa posisi, hanya saja bukaan tersebut ditutupi dengan tirai (gorden), sehingga tidak ada cahaya yang masuk melewatinya. Tujuan dari pemberian tirai tersebut adalah 
TABEL II: Kuat Pencahayaan setempat.

\begin{tabular}{lcccc}
\hline \hline \multicolumn{4}{c}{ Kuat Pencahayaan } & Kesera- \\
Area & $\begin{array}{c}\mathrm{E}_{\text {min }} \\
(\text { Lux })\end{array}$ & $\begin{array}{c}\mathrm{E}_{\text {maks }} \\
(\text { Lux })\end{array}$ & $\begin{array}{c}\mathrm{E}_{\text {rerata }} \\
(\text { Lux })\end{array}$ & $\begin{array}{c}\text { gaman } \\
\mathrm{U}_{\circ}\end{array}$ \\
\hline Rak buku & 17,61 & 146,4 & 81,35 & 0,22 \\
Meja Baca & 60,6 & 126 & 93,5 & 0,65 \\
\hline \hline
\end{tabular}

untuk menghindari terjadinya silau yang berlebihan akibat pencahayaan alami. Karena pada saat dilakukan pengukuran di area jendela dengan kondisi tanpa gorden nilai kuat pencahayaan yang didapatkan berkisar antara 5.000-10.000 lux.

Juga terlihat dalam Tabel I bahwa nilai kuat pencahayaan rata-rata yang terukur pada saat kondisi lampu ruangan menyala hanya sebesar 90,27 lux. Nilai tersebut masih jauh dari standar yang dianjurkan untuk ruang perpustakaan yaitu minimal 300 lux. Penyebab dari rendahnya nilai tersebut adalah kondisi lampu di ruangan yang tidak maksimal, karena terdapat beberapa armatur yang hanya berisi 1 buah lampu dari yang seharusnya 2 buah lampu.

\section{Hasil pengukuran kuat pencahayaan setempat}

Selain pengukuran secara umum, pengukuran kuat pencahayaan juga dilakukan secara setempat yaitu pada bagian meja-meja dan rak-rak yang terdapat di area baca. Pengukuran setempat ini dilakukan untuk mengetahui nilai kuat pencahayaan secara lebih rinci dari bagian area meja baca dan rak buku. Di Perpustakaan ITS terdapat 91 rak buku dan 46 meja baca. Hasil pengukuran untuk kuat pencahayaan setempat dapat dilihat pada Tabel II.

Dari Tabel II terlihat bahwa kuat pencahayaan yang terukur belum memenuhi standar yang dianjurkan yaitu 300 lux. Sementara nilai keseragaman (difusifitas) cahaya pada area rak buku sebesar 0,22 yang menunjukkan jauh dari standar yang seharusnya untuk ruang perpustakaan yaitu sebesar 0.6. Penyebab utama ketidakseragaman tersebut adalah posisi rak buku yang berdekatan satu sama lain (Gambar 4). Selain itu, mayoritas rak yang berada jauh dari jendela nilai kuat pencahayaannya lebih rendah dibandingkan dengan yang dekat jendela. Cahaya yang seharusnya mengenai rak tersebut terhalang karena pemosisian rak yang miring dan menyebabkan terjadinya pembayangan satu rak terhadap rak yang lain pada bagian tertentu. Sementara nilai keseragaman untuk area meja cukup seragam yang ditunjukkan oleh nilai keseragaman melebihi dari 0,6. Hal tersebut disebabkan oleh posisi (penempatan) meja baca yang tepat berada di bawah lampu.

\section{Perbandingan hasil pengukuran dan hasil simulasi existing}

Simulasi kondisi existing dilakukan untuk memvalidasi (membandingkan) nilai kuat pencahayaan antara hasil pengukuran dengan hasil simulasi seperti kondisi seperti pada pengukuran. Pada simulasi, data mengenai dimensi ruangan, warna permukaan ruangan, jenis lampu, jumlah lampu, dan posisi peletakan lampu sesuai dengan yang ada di dalam

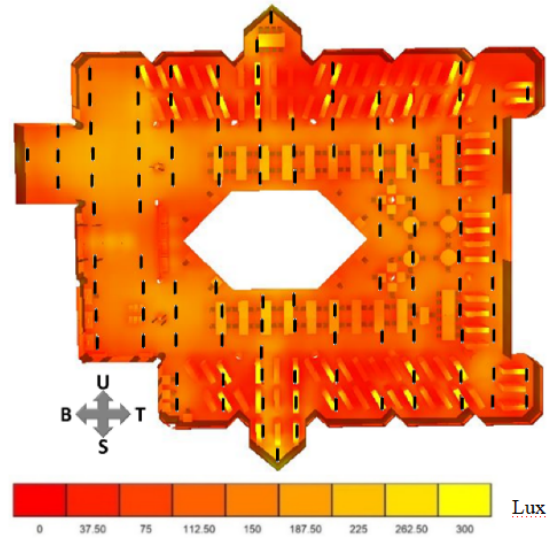

Gambar 4: Hasil simulasi kuat pencahayaan kondisi existing model false color.

TABEL III: Perbandingan hasil pengukuran kondisi existing dengan hasil simulasi exisitng.

\begin{tabular}{lcccc}
\hline \hline $\begin{array}{l}\text { Objek } \\
\text { Pengu- } \\
\text { kuran }\end{array}$ & $\begin{array}{c}\mathrm{E}_{\text {min }} \\
(\text { Lux })\end{array}$ & $\begin{array}{c}\mathrm{E}_{\text {maks }} \\
\text { (Lux) }\end{array}$ & $\begin{array}{c}\mathrm{E}_{\text {rerata }} \\
\text { (Lux) }\end{array}$ & $\begin{array}{c}\text { Kesera- } \\
\text { gaman } \\
\mathrm{U}_{\circ}\end{array}$ \\
\hline & & & & \\
Existing & 43,3 & 130,8 & 90,27 & 0,48 \\
Simulasi & 75 & 247 & 168 & 0,479 \\
\hline \hline
\end{tabular}

ruangan. Gambar 5 menunjukkan hasil simulasi pencahayaan sesuai dengan kondisi existing.

Berdasarkan Gambar 4, terlihat adanya perbedaan kuat pencahayaan di beberapa area secara simulasi. Hal ini disebabkan oleh kemampuan lampu dalam memancarkan lumen yang sudah berkurang seiring dengan umur pemakaian lampu. Berdasarkan Gambar 4, terlihat bahwa keseragaman dari kuat pencahayaan di ruangan belum merata. Sementara nilai kuat pencahayaan rata-ratanya masih di bawah standart yaitu sekitar 90 Lux. Penyebab kurangnya keseragaman tersebut karena posisi penempatan lampu yang kurang tepat. Perbandingan antara hasil pengukuran kondisi existing dan hasil simulasi ditampilkan pada Tabel III.

Berdasarkan data pada Tabel III, terdapat selisih yang cukup besar antara hasil simulasi untuk kondisi eksisting dengan hasil pengukuran. Hal itu disebabkan karena pada saat simulasi lampu yang digunakan dalam kondisi maksimalnya. Sedangkan untuk lampu yang digunakan di dalam ruangan telah mengalami pengurangan kemampuan akibat penggunaannya selama di ruangan. Untuk itu diperlukan perhitungan kembali agar perbandingan hasil simulasi dan hasil pengukuran mendekati 1. Berikut ini adalah perhitungan untuk mencari nilai LLF dan CU untuk menyesuaikan hasil pengukuran dengan hasil simulasi.

Data yang diketahui:

- Luas Ruang Baca $=1381,58 \mathrm{~m}^{2}$

- Kuat pencahayaan rata-rata $=90,27 \mathrm{~m}^{2}$

- Fluks luminus 19 Lampu Philips 2xTL-D36W/54-765 
$@ 5000 \mathrm{~lm}=95000 \mathrm{~lm}$

- Fluks luminus 112 lampu Philips 1Xtl-D36w/54-765 @ $2500 \mathrm{~lm}=280000 \mathrm{~lm}$

- Fluks luminus 6 Lampu Philips RS061B 1xLED tipe 5-36-/830@480=28801m

- Fluks luminus total lampu $=95000+280000+2880=$ $377880 \mathrm{~lm}$

$$
L L F=L L D \times L D D \times B F
$$

Untuk ruang perpustakaan lantai 5 ITS sendiri tergolong cukup bersih sehingga nilai LDD-nya adalah 0,9 (dilihat dari grafik pada Gambar 2).

$\mathrm{LLD}=9$ jam $\times 360$ hari $=3240$, dari tabel sekitar $85 \%$

Nilai BF bervariasi antara 0,9-1 dan diambil sebesar 0,9.

$$
\begin{aligned}
L L F & =0,85 \times 0,9 \times 0,9=0,69 \\
C U & =\frac{E_{A V} \times A}{L L F \times \Phi_{t o t}} \\
C U & =\frac{90,27 \times 1381,58}{0,69 \times 377880}=0,48 \\
E_{\text {av.penurunan }} & =E_{\text {av.simulasi }} \times C U \\
E_{\text {av.penurunan }} & =168 \times 0,48=80,64
\end{aligned}
$$

Hasil simulasi yang diperoleh dikalikan dengan $\mathrm{CU}$ sehingga diperoleh perbandingan antara kuat pencahayaan hasil simulasi dengan hasil pengukuran sebagai berikut.

$$
\frac{E_{\text {av.simulasi }}}{E_{\text {av.pengukuran }}}=\frac{80,64}{90,27}=0,9
$$

Dari perbandingan tersebut diperoleh nilai perbandingan antara hasil pengukuran dan simulasi sebesar 0,9 yang menunjukkan bahwa hasil simulasi dengan menggunakan DIALux sudah sesuai dengan hasil pengukuran. Sedangkan untuk jumlah daya yang dipakai dapat diperoleh dari perkalian antara banyaknya jumlah lampu dengan besar daya yang dibutuhkan oleh setiap lampu.

$$
\begin{aligned}
112 \text { lampu } \times 43 \text { watt } & =4816 \text { watt } \\
19 \text { lampu } \times 85 \text { watt } & =1615 \text { watt } \\
6 \text { lampu } \times 6 \text { watt } & =36 \text { watt } \\
\text { Daya total } & =6467 \text { watt. }
\end{aligned}
$$

Berdasarkan hasil perhitungan tersebut, diperoleh besarnya energi perdetik atau daya yang terpakai adalah 6467 Watt. Nilai ini cukup besar sehingga perlu dilakukan desain ulang terkait jenis (tipe), posisi dan jumlah lampu yang dipakai agar pemakain energi menjadi lebih sedikit.

\section{Simulasi perbaikan desain pencahayaan}

Pada penelitian ini telah dilakukan beberapa simulasi dengan mengganti jenis, jumlah, dan posisi peletakan lampu di dalam

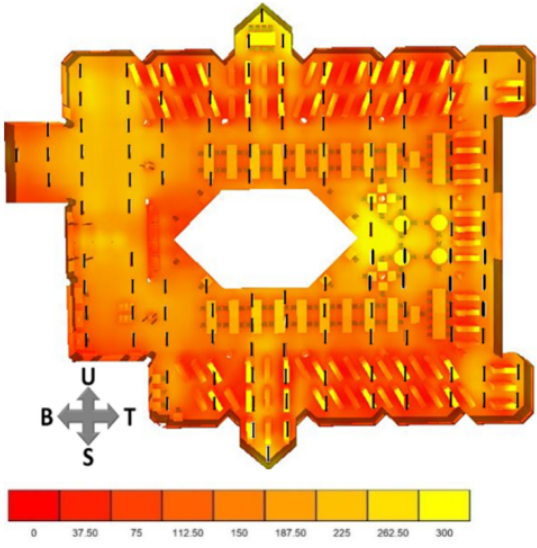

Gambar 5: Hasil simulasi kuat pencahayaan perbaikan pertama model false color.

ruangan. Dari beberapa simulasi tersebut diambil dua simulasi perbaikan. Simulasi pertama digunakan untuk mengetahui hasil kuat pencahayaan ruangan dengan kondisi lampu pada performa maksimal. Sedangkan simulasi kedua menggambarkan hasil simulasi terbaik dari beberapa simulasi yang telah dilakukan.

\section{Simulasi perbaikan pertama}

Pada simulasi perbaikan pertama ini dilakukan penambahan lampu pada beberapa armature lampu yang seharusnya ada yaitu masing-masing armatur berisi 2 lampu meskipun pada kondisi nyatanya (pengukuran) hanya berisi 1 buah lampu. Penggantian dilakukan untuk mengetahui bagaimana kondisi terbaik ruangan pada saat pemasangan lampu di awal perencanaan atau desain. Jumlah total lampu yang digunakan totalnya adalah sebanyak 131 lampu, dengan rincian tipe 1xTLD36W/54-765 sebanyak 63 lampu dan untuk tipe 2xTLD36W/54-765 sebanyak 68 lampu. Gambar 5 menunjukkan hasil simulasi perbaikan untuk kondisi awal desain pencahayaan.

Berdasarkan Gambar 5 terlihat pula terjadinya peningkatan nilai kuat pencahayaan yang tampak pada degradasi warna yang sudah lebih mendekati warna kuning. Namun masih terdapat beberapa area yang terlihat berwarna merah. Hal tersebut dapat terjadi akibat posisi peletakan antar rak buku yang cukup berdekatan, sehingga menyebabkan bayangan dari beberapa rak mengenai area buku-buku di rak belakangnya. Posisi penempatan rak yang tepat akan dapat mengurangi bahkan menghilangkan terjadinya peristiwa pembayangan pada area rak baca. Selain itu dapat dilakukan perbaikan dengan mengganti pencahayaan secara langsung yang digunakan pada ruangan dengan pencahayaan secara tidak langsung. Yaitu dengan cara mengarahkan lampu pada area atap. Namun perbaikan tersebut juga harus dibarengi dengan perawatan atap yang baik akibat intensitas cahaya yang dikenakan pada atap cukup besar. Berdasarkan Gambar 5, dapat diketahui nilai pencahayaan maksimum, pencahayaan minimum serta 
TABEL IV: Perbandingan hasil pengukuran kondisi existing dengan hasil simulasi perbaikan pertama.

\begin{tabular}{|c|c|c|c|c|}
\hline \multirow{2}{*}{$\begin{array}{l}\text { Objek } \\
\text { Pengu- } \\
\text { kuran }\end{array}$} & \multicolumn{3}{|c|}{ Kuat Pencahayaan } & \multirow{2}{*}{$\begin{array}{c}\text { Kesera- } \\
\text { gaman } \\
\mathrm{U}_{\circ}\end{array}$} \\
\hline & $\begin{array}{l}\mathrm{E}_{\text {min }} \\
\text { (Lux) }\end{array}$ & $\begin{array}{c}\mathrm{E}_{\text {maks }} \\
\text { (Lux) }\end{array}$ & $\begin{array}{c}\mathrm{E}_{\text {rerata }} \\
\text { (Lux) }\end{array}$ & \\
\hline Existing & 43,3 & 130,8 & 90,27 & 0,48 \\
\hline Simulasi 1 & 100 & 360 & 201 & 0,47 \\
\hline
\end{tabular}

kerataan kuat pencahayaan yang terjadi hasil simulasi seperti terlihat pada Tabel IV.

Berdasarkan pada Tabel IV, dalam simulasi yang dilakukan dapat ditentukan jumlah energi listrik yang dipakai seperti pada perhitungan berikut:

$$
\begin{aligned}
63 \text { lampu } \times 43 \text { watt } & =2709 \text { watt } \\
68 \text { lampu } \times 85 \text { watt } & =5780 \text { watt } \\
6 \text { lampu } \times 6 \text { watt } & =36 \text { watt } \\
\text { Daya total } & =8525 \text { watt } .
\end{aligned}
$$

Berdasarkan hasil perhitungan untuk kondisi eksisting tersebut, daya listrik yang dibutuhkan menjadi lebih besar yaitu 8525 Watt, sementara nilai kemerataan masih kurang $(0,47)$. Hal ini terlihat jelas pada area rak buku (Gambar 5). Dengan kondisi tersebut pencahayaan berupa lampu yang ada di perpustakaan perlu digantikan dengan lampu jenis lain terutama pada area rak buku dan meja baca guna meningkatkan kuat pencahayaannya sehingga memenuhi standard yang dianjurkan. Penggantian lampu dapat dilakukan dengan menggunakan lampu LED yang dapat memancarkan fluks luminus yang lebih besar dengan daya yang dibutuhkan lebih rendah dibandingkan dengan lampu TL. Sehingga diharapkan akan dapat mengurangi pemakaian energi dan dapat menghemat pengeluaran biaya pemakaian lampu di ruangan.

2. Simulasi perbaikan kedua

Simulasi perbaikan kedua dilakukan dengan mengganti semua lampu yang terdapat di ruangan menggunakan lampu philips tipe LL121X 1xLED42S/840-O yang memancarkan fluks luminous sebesar 4200 lumen dan daya untuk 32 Watt tiap lampunya. Selain itu dilakukan penambahan beberapa lampu pada area rak buku guna meningkatkan kuat pencahayaan yang dihasilkan dari proses simulasi. Gambar 7 menunjukkan penempatan lampu dan hasil simulasinya.

Merujuk pada Gambar 6, nilai kuat pencahayaan dan tingkat keseragaman yang diperoleh memenuhi standard untuk titik-titik pengukuran secara umum. Selain itu degradasi warna cukup merata pada area meja baca namun masih kurang untuk area rak buku. Berdasarkan Gambar 6 masih terlihat adanya area yang memiliki nilai kuat pencahayaan kurang dari 10 lux. Hal ini disebabkan oleh penempatan rak yang kurang tepat

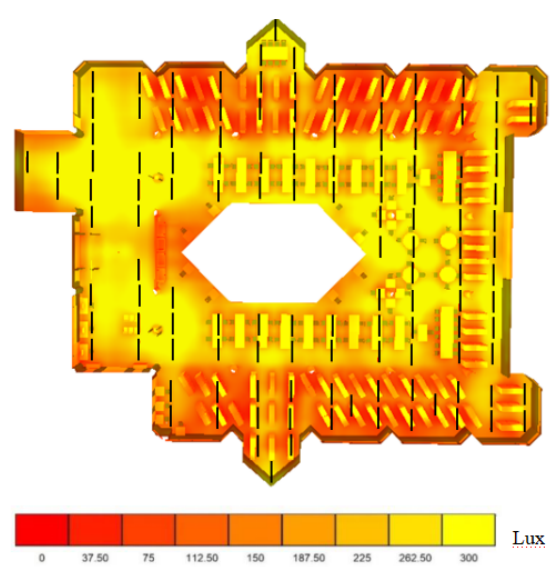

Gambar 6: Hasil simulasi kuat pencahayaan perbaikan kedua model false color.

TABEL V: Perbandingan hasil pengukuran kondisi existing dengan hasil simulasi perbaikan kedua.

\begin{tabular}{lcccc}
\hline \hline $\begin{array}{l}\text { Objek } \\
\text { Pengu- } \\
\text { kuran }\end{array}$ & \multicolumn{4}{c}{ Kuat Pencahayaan } \\
$\begin{array}{l}\mathrm{E}_{\text {min }} \\
(\text { Lux })\end{array}$ & $\begin{array}{c}\mathrm{E}_{\text {maks }} \\
\text { (Lux) }\end{array}$ & $\begin{array}{c}\mathrm{E}_{\text {rerata }} \\
\text { (Lux) }\end{array}$ & $\begin{array}{c}\text { Kesera- } \\
\text { gaman } \\
\mathrm{U}_{\circ}\end{array}$ \\
\hline Existing & 43,3 & 130,8 & 90,27 & 0,48 \\
Simulasi 1 & 213 & 441 & 344 & 0,62 \\
\hline \hline
\end{tabular}

sehingga terbentuk bayangan di area tersebut. Adapun hasil perbaikan simulasi ke-2, secara umum ditampilkan pada Tabel V.

Berdasarkan pada Tabel V, terjadi peningkatan nila keseragaman intensitas cahaya pada area perpustakaan yang cukup signifikan dibandingkan dengan simulai ke1 , yaitu dari 0,48 menjadi 0,64. Sementara dari hasil simulasi di titik-titik pengukuran pada area meja baca dan area rak buku terlihat pada Tabel VI.

Pada Tabel VI dapat dilihat bahwa dari hasil simulasi untuk kuat pencahayaan pada meja baca sudah memenuhi standart dengan nilai kuat pencahayaannya di atas 300 lux. Hal tersebut dikarenakan beberapa lampu yang digunakan posisinya tepat berada di atas meja baca sehingga pancaran cahaya dari lampu langsung mengarah pada meja. Sedangkan untuk area rak buku, nilai kuat pencahayaan rata-rata yang diperoleh

\begin{tabular}{|c|c|c|c|c|}
\hline \multirow{2}{*}{$\begin{array}{l}\text { Objek } \\
\text { Pengu- } \\
\text { kuran }\end{array}$} & \multicolumn{3}{|c|}{ Kuat Pencahayaan } & \multirow{2}{*}{$\begin{array}{c}\text { Kesera- } \\
\text { gaman } \\
U_{\circ} \\
\end{array}$} \\
\hline & $\begin{array}{l}\mathrm{E}_{\text {min }} \\
\text { (Lux) }\end{array}$ & $\begin{array}{c}\mathrm{E}_{\text {maks }} \\
\text { (Lux) }\end{array}$ & $\begin{array}{c}\mathrm{E}_{\text {rerata }} \\
\text { (Lux) }\end{array}$ & \\
\hline Meja baca & 248 & 510 & 406 & 0,55 \\
\hline Rak buku & 6,24 & 380 & 95 & 0,07 \\
\hline
\end{tabular}
hanya sebesar 95 lux dengan keseragamannya 0,07. Se-

TABEL VI: Perbandingan hasil pengukuran kondisi pada meja baca dan rak buku, hasil simulasi perbaikan kedua. 
lain itu beberapa rak pada titik pengukuran berada di dekat tiang sehingga cahaya lampu yang seharusnya dapat mengenai rak terhalang oleh tiang-tiang tersebut. Pemindahan posisi rak saja dirasa belum dapat maksimal jika tidak dibarengi dengan penambahan instalasi lampu di area rak buku sehingga dapat diperoleh peningkatan kuat pencahayaan dan keseragamannya.

Berdasarkan pada simulasi perbaikan ke-2, dapat dilakukan perhitungan pemakaian daya listrik yang dibutuhkan:

$$
\begin{aligned}
129 \text { lampu } \times 32 \text { watt } & =4128 \text { watt } \\
6 \text { lampu } \times 6 \text { watt } & =36 \text { watt } \\
\text { Daya total } & =4164 \text { watt. }
\end{aligned}
$$

Berdasarkan pada hasil perhitungan daya pada penggantian lampu menggunakan LL121X 1xLED42S/840 O, terjadi membutuhkan daya sebesar 4164 Watt. Jika dibandingkan dengan penggunaan daya pada desain awal (6467 Watt), hasil simulasi ke-2 diperoleh efisiensi penggunaan energi listrik mencapai $36 \%$. Meskipun dibutuhkan biaya yang cukup besar untuk penggantian lampu tersebut, namun dengan nilai luat pencahayaan yang memenuhi standard dengan umur pakai lampu LED yang lebih lama akan dapat mengurangi biaya pemakaian lampu dalam beberapa tahun ke depan. Jika dilakukan penggantian pada ruangan di latai yang lain akan diperoleh penghematan energi yang cukup besar untuk ke depannya, meskipun dibutuhkan dana yang cukup besar di awal.

\section{SIMPULAN}

Dari penelitian yang telah dilakukan diperoleh simpulan bahwa hasil pengukuran pencahayaan pada kondisi existing (sebenarnya) belum memenuhi standard yaitu kuat pencahayaannya 90,27 lux dan distribusi keseragamannya 0,48. Perbandingan nilai kuat pencahayaan hasil pengukuran dan hasil simulasi kondisi existing bernilai 0,85. Hasil simulasi pertama (kondisi awal desain) diperoleh nilai kuat pencahayaan rata-rata sebesar 201 lux, kemerataan 0,47 serta daya lampu total adalah 8525 watt. Hasil simulasi kedua dengan menggunakan lampu 32 Watt sebanyak 129 lampu mampu menghasilkan nilai kuat pencahayaan rata-rata sebesar 344 lux dan keseragaman 0,62. Pada desain kedua, terjadi penurunan penggunaan daya listrik dari kondisi existing 6467 watt menjadi 4164 watt atau $36 \%$ lebih efisien.
[1] C.J. Kibert, "Sustainable construction: green building design and delivery", 3rd ed. Hoboken, N.J: John Wiley \& Sons, 2012

[2] S.A. Maislin, and J.R. Gilmore, "Lighting Handook", edisi 9. IESNA, Amerika, 2000

[3] SNI_03-2396-2001, "Perancangan Pencahayaan", BSN, Indonesia, 2001

[4] Zoomtobel, "The Lighting Handbook", Zumtobel Lighting GmbH, Austria, 2018

[5] Argus, "Light-and-Lighting-Control-in-Greenhouses", Argus control system, Coumbia, 2010.

[6] Dana Beckwith, "Solid state Lighting Calculating Light Loss Factors", DKS Associates, Portland, 2016.

[7] SNI-16-7062-2004, "Pengukuran-pencahayaan”, BSN, Indonesia 2004

[8] EN 12464-1, "Light and lighting: Lighting of work places, Part 1: Indoor work places", NSAI Standart, 2011 